\title{
Cytogentic and bacteriological study of raw and magnetic milk
}

$$
\text { دراسة الوراثة الخلوية والميكروبية للحليب الخام والممغنط }
$$

\section{Sarab H. Khlil Wafaa A. Al-Kabi Heiam K. Muhamed Buthaiena Shahid College of medicine/ Baghdad University

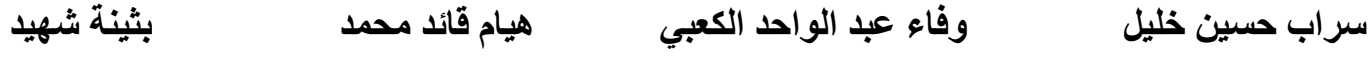 كلية الصيدلة / جامعة بغاد الكي}

\begin{abstract}
$\mathbb{T}^{2}$

his study was conducted to investigate the efficiency of magnetic system in milk sterilization. This was done using bacteriological, (total microbial count) and cytogenetic (mitotic index and chromosomal aberration of bone marrow) investigations. Results indicated a reduction in total milk microbial count. On the other hand, mitotic index was increased and chromosomal aberration in bone marrow was decreased in magnetic milk as compared with raw milk. In conclusion, milk sterilization might perform using magnetic field application.

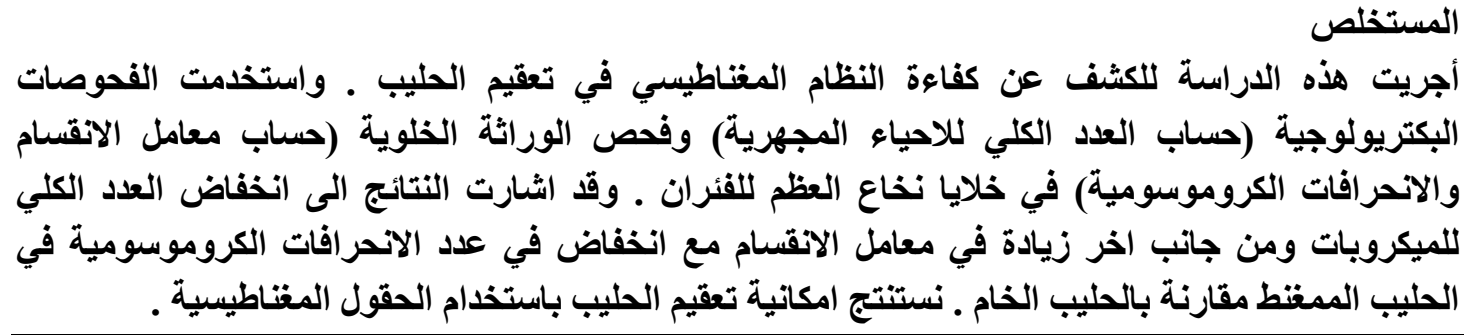

\section{Introduction}

Although, milk is sterile within the udder, it might be bacterial contaminated before its secreted from the udder. Except for mastitis that caused by infectable types of bacteria (Staphylococcus aureus, Streptococcus uberis and Coliform spp), the bacteria in this position is undeteimable and harmless. Other microbial contamination may take place during milking, handing, storage and pre-processing operations [1]. Dairy plants always used pasteurization to prevent bacterial contamination. However, this process may degrade some of milks valuable nutrients [2]. Food preservation act either to kill or deny microorganisms. Food preservation includes heating, cooking, smoking, salting and drying. Currently, food preservation factors used modern methods like microwave cooking, plasma types of radiation, such as ultraviolet light and magnetic fields [3, 4]. Static magnetic fields (SMF) and oscillating magnetic fields (OMF) have been used as a good method for microbial inactivation. For SMF, the magnetic field intensity is constant with time, whereas, OMF is usually applied in the form of either constant or decaying amplitude sinusoidal waves [5].

Preliminary studies have shown that SMF alone does not have an active effect to prevent microbial cell growth and conditions regardless of magnetic intensity [6]. Moreover, cell cycle distribution was not influenced by extremely SMF (Up to 10 Telsa). On the other hand, SMF may cause DNA damage which can be evaluated by determination of the frequency of micronucleus formation [7]. 
The objective of this study was to evaluate the anti-microbial effect of raw milk using $\mathrm{SMF}$, and to examine the influence of this magnetic milk on chromosomal aberration of mice.

\section{Material \&methods}

Raw milk was collected from cow in sterile condition. In laboratory, the raw milk was divided into two parts. First part was treated with magnetic system (2000 Gauss $\left.{ }^{*}\right)$, and the other was regard as control. For microbial test cultured samples of magnetic milk and control were diluted and grown in nutrient, Mckoncy, blood, chocolate agar and sabaurroid. Number of colonies was using the pour plate method or spread plate procedure [8].

For cytogenetic test, twenty four mice were divided equally into two groups A and B. Twelve mice of group A were subdivided equally into 3 subgroups of 4 mice each and drinking raw milk. Mice's in group B were subdivided similarly as in group A and drinking magnetic milk.

In both groups, first, second, and third subgroups were killed after two, six and twelve weeks respectively.

For chromosomal preparations, metaphase spreads were prepared according to Allen method [9]. Mitotic index and chromosomal aberration (breaks, ring, centric and dicentric) were performed in each metaphase spread. Staining of spread using Geimsa stain was also used. One hundred metaphase spread was examined for each mice using X100 power microscope.

\section{Statistical analyses}

Data were statistically analyzed using student test and ANOVA analysis of variance [10].

\section{Result \&Discussion:}

Studies concerning the exposure of raw milk to 2000 Gauses static magnetic field revealed a significantly decreasing in bacterial count in magnetic exposed milk. The bacterial population in raw and magnetic milk was identified and counted the numbers of bacterial colonies for them. Presently, the bacterial isolations included Listeria momocytogenes, Staphylococcus aureus, Lactobcillus delbrueckii, Streptococcus thermophillus, Aspergillus niger and Escherichia coli Table (1), showed the mean values of numbers of colonies in both raw and magnetic milk. There was decrease in numbers of colonies in magnetic milk ascompared to the raw milk. [12] found the growth rate of staphyllcoccus aureus was decreased after exposure to magnetic field. Also, [13] reported that Streptococcus thermophilus and E. coli in milk were reduced from 25,000 to 970 cells/ ml. after exposure to magnetic field.

There are a few literatures in that subject as method is safe and new for sterility the milk which could reduce number of microorganism without thermal method $[13 ; 14$; $15 ; 16 ; 17 ; 18 ; 19]$. And [5] explained the inactivation mechanisms for cells placed in magnetic field by two theories. First, theory stated that "weak" oscillating magnetic fields (OMF) could lose the bonds between ions and proteins. Many proteins vital to the cell metabolism contain ions. In the presence of a steady background magnetic field such as that of the earth, the biological effects of magnetic field are more

${ }^{*} 1$ Telsa $=104$ Gauss [ 11] 
A second theory considers the effect of magnetic field on calcium ions bound in calcium-binding proteins, such as calmodulin. The calcium ions continually vibrate about an equilibrium position in the binding site of calmodulin. A steady magnetic field to calmodulin causes the plane of vibration to rotate, or proceed in the direction of magnetic field at a frequency that is exactly = of the cyclotron frequency of the bound calcium. Adding a "wobbling" magnetic field at the cyclotron frequency disturbs the precision to such an extent that it loosens the bond between the calcium ion and the calmodulin[5].

Therefore; the inactivation of microorganisms may be based on the theory that the magnetic field may couple energy into the magnetically active parts of large critical molecules such as DNA. Within 5-50 T range. Several oscillations and collective assembly of enough local activation may result in the breakdown of covalent bonds in the DNA molecule and inhibition of the growth of microorganisms [20]. Also, high intensity magnetic fields can affect membrane fluidity and other properties of cells [21]. In contrast, $[14,13,22]$ found no evidence to clearly state the microbial inactivation efficiency of magnetic field or to make any predictions about its effects on microbial populations.

Table (1): Total microorganism count pre and post SMF treatment.

\begin{tabular}{|c|c|c|c|}
\hline & Microorganism & $\begin{array}{c}\text { Total count befor } \\
\text { magnetic }\left(\text { cell } / \mathrm{mm}^{3}\right)\end{array}$ & $\begin{array}{c}\text { Total count after } \\
\text { magnatic }\left(\operatorname{cell} / \mathbf{~ m m}^{3}\right)\end{array}$ \\
\hline 1 & Listeria monocytogenes & $77 \times 10$ & $43 \times 10$ \\
\hline 2 & Escherichia coli & $380 \times 10$ & 0 \\
\hline 3 & Staphllycoccus aureus & $215 \times 10$ & $190 \times 10$ \\
\hline 4 & Lactobacillus delbrueckii & $270 \times 10$ & $200 \times 10$ \\
\hline 5 & Aspergillus niger & $20 \times 10$ & $15 \times 10$ \\
\hline \multirow[t]{2}{*}{6} & Streptococcus thermophillus & $118 \times 10$ & $80 \times 10$ \\
\hline & Total & $1080 \times 10$ & $528 \times 10$ \\
\hline
\end{tabular}

In cytogenetic studies observing various chromosomal aberrations in the bone marrow of mice drinking a dosage of magnetic milk. An optimum mitotic of $(4.4167 \pm 0.154)$ and (4.9500 \pm 0.212 ) Table (2) was obtained from mice drinking s a dosage of raw and magnetic milk respectively. The values of mitotic index are an indication of the degree of cytotoxicity a reduction greater than 50 percent in the mitotic index value when compared to control indicates the cytotoxic nature of the test substance [23]. In the present study, there was a significantly increase in the mitotic index value of magnetic milk compared with raw milk. The increase of mitotic index in bone marrow in normal range that was evidence of the magnetic milk has healthy effect on the cells. Thus, the potential energy of cells is increased from take of the dosage magnetic water and positive effect on proliferations cells [24]. This reflects that the magnetic energy has an influence on milk similar for water and no alterations on the chemical structure of milk. 
Table(2): Effect of magnetic milk on mitotic index in bone marrow of mice.

\begin{tabular}{|c|c|}
\hline Effecting factors & Mean \pm std. error \\
\hline \multicolumn{2}{|c|}{ Type of milk } \\
\hline Raw milk & a $4.416 \pm 0.154$ \\
\hline Magnetic milk & ${ }^{b} 4.950 \pm 0.212$ \\
\hline \multicolumn{2}{|l|}{ periods } \\
\hline Two weeks & ${ }^{\mathrm{a}} 4.250 \pm 0.186$ \\
\hline Six weeks & ${ }^{\mathrm{a}} \mathrm{b} 4.725 \pm 0.136$ \\
\hline Twelve weeks & ${ }^{b} 5.075 \pm 0.300$ \\
\hline \multicolumn{2}{|c|}{ Interaction between type of milk and the periods } \\
\hline Two weeks of raw milk & ${ }^{\mathrm{a}} 4.150 \pm 0.313$ \\
\hline Six weeks of raw milk & ${ }^{\mathrm{a}} 4.750 \pm 0.210$ \\
\hline Twelve weeks of raw milk & ${ }^{\mathrm{a}} 4.350 \pm 0.240$ \\
\hline Two weeks of Magnetic milk & ${ }^{\mathrm{a}} 4.350 \pm 0.240$ \\
\hline Six weeks of Magnetic milk & ${ }^{\mathrm{a}} 4.700 \pm 0.204$ \\
\hline Twelve weeks of Magnetic milk & ${ }^{b} 5.800 \pm 1.108$ \\
\hline Total & $4.683 \pm 0.140$ \\
\hline
\end{tabular}

Various chromosomal aberrations were observed in the bone marrow of mice drinking of magnetic milk comparing with mice drinking dosage of raw milk for three periods $(2,6,12)$ weeks. Chromosomal aberration could be classified into "numerical" and "structural" aberrations. In present study, the structural aberration included break, ring chromosome, a centric fusion and dicentric fusion.

Table (3) observed the mean values of break in the bone marrow cells of mice drinking dosage of magnetic milk for $(2,6,12)$ weeks. There was a significant (pco.os) decrease after 12 weeks in magnetic milk dosage in comparison with the mice drinking dosage of raw milk.

Table (3) noted the mean values of ring chromosome in cells of mice drinking dosage of magnetic milk for 2, 6 and 12 weeks. There was a significant decrease in total mean of magnetic milk comparing to the raw milk.

Table (3), Showed the mean values of a centric fusion in cells after $(2,6,12)$ weeks of magnetic dosage. There was a significant (pco.os) reduction by magnetic milk dosage after two and 12 weeks comparing to raw milk dosage. Also there was a significant decrease in total mean values of magnetic milk comparing the raw milk dosage.

The magnetic fields causing many effects on chemical structure for many molecules in milk like water protein and vitamin. The magnetic field disrupts the hydrogen bounding, increase the evaporation rate of water and dissolution rate of oxygen. It can also increase proton spin relaxation [24] Therefore; the magnetic field has a good effect on raw milk for as sterilization method. [25] Found that magnetic field has a good means to repair DNA system in the living cells. [26], observed the role of magnetic water in stop of toxin secretion which result from the anaerobic respiration [27]. Therefore the body can treat itself from some diseases as hypertension, headache, diabetes milts and the aging [28].

From our result, magnetic fields have killing effect on microorganisms. And no effect in mitotic index and chromosomal aberrations, it are indicate that milk tested do not 
induce cytotoxicity by exposure to magnetic field .Also suggested using magnetic field as methods for materials sterilization which destroy in heating such milk.

Table (3): Effect of magnetic milk on chromosomal aberrations of mice.

\begin{tabular}{|c|c|c|c|c|}
\hline $\begin{array}{l}\text { Type of chromosomal } \\
\text { aberration }\end{array}$ & Breaks & Ring & Acentric & dicentric \\
\hline Effecting factors & Mean \pm std. error & Mean \pm std. error & Mean \pm std. error & Mean \pm std. error \\
\hline \multicolumn{5}{|c|}{ Type of milk } \\
\hline Raw milk & ${ }^{\mathrm{a}} 1.183 \pm 0.068$ & ${ }^{\mathrm{a}} \mathbf{0 . 1 1} \pm \mathbf{0 . 0 3}$ & ${ }^{\mathrm{a}} 0.2083 \pm 0.034$ & ${ }^{\mathrm{a}} 0.125 \pm 0.031$ \\
\hline Magnetic milk & ${ }^{\mathrm{a}} 1.0083 \pm 0.061$ & ${ }^{b} 0.058 \pm 0.015$ & ${ }^{b} 0.1083 \pm 0.050$ & ${ }^{\mathrm{a}} 0.067 \pm 0.023$ \\
\hline \multicolumn{5}{|c|}{ Periods } \\
\hline Two weeks & ${ }^{\mathrm{a}} 1.075 \pm 0.059$ & ${ }^{\mathrm{a}} \mathbf{0 . 1 0 0} \pm \mathbf{0 . 0 2 7}$ & ${ }^{\mathrm{ab}} 0.1625 \pm 0.037$ & ${ }^{\mathrm{a}} 0.075 \pm 0.025$ \\
\hline Six weeks & ${ }^{\mathrm{a}} 1.100 \pm 0.200$ & ${ }^{\mathrm{a}} 0.075 \pm \mathbf{0 . 0 2 5}$ & ${ }^{b} \mathbf{0 . 0 8 8} \pm \mathbf{0 . 0 2 9}$ & ${ }^{\mathrm{a}} 0.088 \pm 0.040$ \\
\hline Twelve weeks & ${ }^{\mathrm{a}} 1.1125 \pm 0.120$ & ${ }^{\mathrm{a}} \mathbf{0 . 0 8 8} \pm \mathbf{0 . 0 2 3}$ & $\operatorname{ac0} .225 \pm 0.045$ & ${ }^{\mathrm{a}} \mathbf{0 . 1 2 5} \pm \mathbf{0 . 0 3 7}$ \\
\hline \multicolumn{5}{|c|}{ Interaction between type of milk and the periods } \\
\hline Two weeks of raw milk & ${ }^{a b} 1.100 \pm 0.108$ & ${ }^{\mathrm{a}} 0.125 \pm 0.048$ & ${ }^{\text {acde }} 0.225 \pm 0.048$ & ${ }^{\mathrm{a}} \mathbf{0 . 1 0 0} \pm \mathbf{0 . 0 4 1}$ \\
\hline Six weeks of raw milk & ${ }^{\mathrm{ab}} 1.100 \pm 0.108$ & ${ }^{\mathrm{a}} 0.100 \pm 0.041$ & acdf $0.100 \pm 0.041$ & ${ }^{\mathrm{a}} \mathbf{0 . 1 0 0} \pm \mathbf{0 . 0 7 1}$ \\
\hline Twelve weeks of raw milk & ${ }^{\mathrm{a}} 1.350 \pm 0.119$ & ${ }^{\mathrm{a}} \mathbf{0 . 1 2 5} \pm \mathbf{0 . 0 2 5}$ & ${ }^{\mathrm{e}} 0.300 \pm 0.041$ & ${ }^{\mathrm{a}} 0.175 \pm 0.048$ \\
\hline Two weeks of Magnetic milk & ${ }^{a b} 1.050 \pm 0.065$ & ${ }^{\mathrm{a}} \mathbf{0 . 0 7 5} \pm \mathbf{0 . 0 2 5}$ & cdf $0.100 \pm 0.041$ & ${ }^{\mathrm{a}} \mathbf{0 . 0 5 0} \pm 0.029$ \\
\hline Six weeks of Magnetic milk & ${ }^{\mathrm{ab}} 1.100 \pm 0.108$ & ${ }^{\mathrm{a}} \mathbf{0 . 0 5 0} \pm \mathbf{0 . 0 2 9}$ & f $0.075 \pm 0.096$ & ${ }^{\mathrm{a}} \mathbf{0 . 0 7 5} \pm \mathbf{0 . 0 4 8}$ \\
\hline $\begin{array}{l}\text { Twelve weeks of Magnetic } \\
\text { milk }\end{array}$ & ${ }^{\mathrm{b}} 0.875 \pm 0.125$ & a $0.050 \pm 0.029$ & bef $0.150 \pm 0.065$ & ${ }^{\mathrm{a}} \mathbf{0 . 0 7 5} \pm \mathbf{0 . 0 3 4}$ \\
\hline Total & $1.0958 \pm 0.048$ & $0.088 \pm 0.014$ & $0.1583 \pm 0.024$ & $0.096 \pm 0.019$ \\
\hline
\end{tabular}

\section{Reference}

1. Al-Takriti, H.H.and Al-Kal,K.M..1984 .Principles of Dairy Processing. Al-mosul University, Iraq.

2. Salaih,A. M. and Al-Omar,M.A.1984. Haelhty Milk.printed in Al-mosul University. Agriculture College. Bagdad university-Iraq.

3. Hofmann, G.A. 1985. Deactivation of microorganisms by an oscillating magnetic field. U.S. Patent 4,524,079.

4. Mahmoud,N.S.;Ghaly,A.E.2004.On-Line sterilization of cheese whey using ultraviolet radiation .Biotechnology Prog;vol 20 (issuez):pp550-560.

5. Pothakamury, U.R., Barbosa-Cánovas, G.V., and Swanson, B.G. 1993. Magneticfield inactivation of microorganisms and generation of biological changes. Food Technol. 47(12):85-93.

6. Lipiec,J.;Jamas,P.;Barabasz,W.(2004).Effect of oscillating magnetic field pulses on the survival of selected microorganisms.Int.Agrophysics, 18,325-328.

7. Miyakoshi, J.2005.. Effects of static magnetic fields at the cellular level. Prog Biophys Mol

8. Cruikshank,R.,Duguid,J.P,Marmion,B.P\&swain,R.H.A(1975).Medical Microbiology,12th,ed.vol 11 London,New York.

9. Allen,J.;Shulier,C. and Latt,S.A. (1977) A simplified technique for invitro analysis of SCE using 5-Brdu Tablets Cyto.Cel.Gel.Genet.,18:231-234.

10. Al-Rawi ,A.(1998).Statistical analysis,Med.College.Italia,20-25.

11. Kinetics of Microbial Inactivation for Alternative Food Processing Technologies Oscillating Magnetic Fields. U. S. Food and Drug Administration Center for Food Safety and Applied NutritionJune 2, 2000. 
12. Gerencser, V.F., Barnothy, M.F., and Barnothy, J.M. 1962. Inhibition of bacterial growth by magnetic fields. Nature, 196:539-541.

13. Moore, R.L. 1979. Biological effects of magnetic fields. Studies with microorganisms. Can. J. Microbiol., 25:1145-1151.

14. Tsuchiya, K., Nakamura, K., Okuno, K., Ano, T. and Shoda, M. 1996. Effect of homogeneous and inhomogeneous high magnetic fields on the growth of Escherichia coli. J Ferment Bioeng 81(4):343-346.

15. Van Nostran F.E.,Reynolds,R.J.and Hedrick,H.G.(1967).Effects of a high magnetic field at different osmotic pressure and temperatures an multiplication of Saccharomyces cervisiae .APPI.Microbiol.,15,561-563.

16. Ray B.;2001.Fundamental food microbiology. Second Edition CRC press, Boca Raton ,London, New York, Washington.

17. Singh,R.P.(2001).Technical elements of new and emerging non-thermal food technologies.FAO. Reoort.

18. Meng-xiang,G.; music, MA .; Guo,K.(2004) Sterilization of the milk by pulsed magnetic fields. Industry Science and Technology Food .Series - Core Journals ISSN: 1002-0306, 07-0076-03.

19. Meng -xiang,G.; Le,M.; Kangquan,G. (2005). Intense pulsed magnetic field on the bactericidal effect of milk and its nutritional composition studies of the impact of Sterilization effect of pulsed magnetic field and its influence on milk nutrient components journals - Journal of Agricultural Engineering core TRANSACTIONS OF THE CHINESE SOCIETY OF AGRICULTURAL ENGINEERING, 03

20. Coughlan, A., Hall, N. 1990. How magnetic field can influence your ions? New Scientist. 8(4):30.

21. Frankel, R. B. and Liburdy, R. P. 1995. Biological effects of static magnetic fields. In Handbook of Biological Effects of Electromagnetic Fields. Polk, C. and Postow, E. (Ed). $2^{\text {nd }}$ Ed. CRC Press. Boca Raton, FL

22. Kimball, G.C. 1937. The growth of yeast on a magnetic fields. J. Bacteriol. 35:109-122.

23. Health Effects Test Guidelines-OPPTS 870.5375.(1998). In Vitro Chromosome Aberration Test -United States Environmental Protection Agency.1-11.

24. Reminick, Howard,ph.D 2000.The Effect of Natu 'Rally Magn Etized water on increase cellular hydration Longevity, ohno institute on water and health Vol.10:6,prescalt,AZ,P:1-6.

25. Maes, M.; Collier, S.; Vandoninck, P.; Scarpa, L.; Verschaeve VITO. (2000). Cytogenetic effects of $50 \mathrm{~Hz}$ magnetic fields of different magnetic flux densitiesA. Vol.21,Issue 8 ,pages 589-596.

26. Fielder (1983).Mechanism of Mutagenesis and carcinogenesis, classification and overview-Mutat.Res.,202:285-306.

27. Wassif,raft kamil,(2003).Magnetic water treatment some diseases.

28. Mahjob (2002). Biochemical and physiological changes which occur in body when set medical magnetic over worn inflammation and pains.07101/MHL/5.htm albayan:/.1998. 